\title{
Dielectric and acoustic properties of modified barium titanate ceramics
}

\author{
K. Bormanis ${ }^{a}$, A. Kalvane ${ }^{a}$, A. I. Burkhanov ${ }^{\text {b }}$, L. Eglite ${ }^{a}$, and R. V. Dikov ${ }^{\text {b }}$ \\ anstitute of Solid State Physics, University of Latvia, Riga, Latvia; ${ }^{\text {b} V o l g o g r a d ~ T e c h n i c a l ~ U n i v e r s i t y, ~}$ \\ Volgograd, Russia
}

\begin{abstract}
A study of cobalt doping effect on the dielectric response and elastic properties of $\mathrm{Ba}_{0.95} \mathrm{~Pb}_{0.05} \mathrm{TiO}_{3}$ solid solution within the range of $20-200{ }^{\circ} \mathrm{C}$ is reported. The results of a study of the dielectric permittivity, dielectric loss and elastic parameters in the samples of ceramic $\mathrm{Ba}_{0.95} \mathrm{~Pb}_{0.05} \mathrm{TiO}_{3}+x \mathrm{CO}_{2} \mathrm{O}_{3}$ in the range of ferroelectric phase transition are presented. Modifying by admixture of $\mathrm{Co}$ is found to change the thermal anomalies of elastic and dielectric properties substantially, as well as to shift the ferroelectric phase transition temperature.
\end{abstract}

ARTICLE HISTORY

Received 14 May 2018

Accepted 31 October 2018

\section{KEYWORDS}

Perovskite; ferroelectrics; barium titanate; doping

\section{Introduction}

The classical ferroelectric $\mathrm{BaTiO}_{3}$ (BT) with perovskite structure has found wide applications in the electronics industry; piezo elements based on BT are widely used for the manufacture of piezo sensors operating in the radiation and reception mode. Although they do not exhibit the best values of dielectric and piezoelectric parameters, these materials attract the attention of developers of end products due to the time-stability of electrophysical properties, and low density and high values of sound velocity in the process of cyclically changing loads [1-5].

BT forms solid solutions with lead titanate of $(1-\mathrm{z}) \mathrm{BaTiO}_{3}-\mathrm{ZPbTiO}_{3}$ type, in which the temperature of the ferroelectric (FE) phase transition (PT) increases as the lead content increases [3-5]. At the same time, the addition of cobalt $\mathrm{Co}^{3+}$ ions to $\mathrm{BaTiO}_{3}$ showed a decrease of the Curie point and a gradual spreading of the PT [6,7]. The doping of $\mathrm{Co}^{3+}$ not only affects the temperature of the phase transition, but also the elastic and dielectric properties of $\mathrm{BaTiO}_{3}$-based ceramics [8, 9]. For example, according to [8], the addition of $\mathrm{Co}^{3+}$ with a mass of up to $1 \%$ leads to damping of the mechanical losses and smoothing of the anomaly of the elasticity modulus.

Thus, solid solutions systems based on BT remain relevant both from the fundamental (for the study of processes during phase transformations) and application point of view, taking into account the widening range of their use during the manufacturing of various devices.

The purpose of this paper is to establish the peculiarities in the dielectric response of a solid solution and in the behaviour of the velocity of longitudinal ultrasonic waves in 
Table 1. Unit cell volume, density, grain size and Young's modulus of $\mathrm{Ba}_{0.95} \mathrm{~Pb}_{0.05} \mathrm{TiO}_{3}+\mathrm{xCO}_{2} \mathrm{O}_{3}$ samples.

\begin{tabular}{lcccc}
\hline Composition & $\begin{array}{c}\text { Unit cell } \\
\text { volume, } \AA^{3}\end{array}$ & $\begin{array}{c}\text { Density } \rho, \\
\mathrm{g} / \mathrm{cm}^{3}\end{array}$ & $\begin{array}{c}\text { Mean grain } \\
\text { linear size, } \mu \mathrm{m}\end{array}$ & $\begin{array}{c}\text { Young's modulus } \mathrm{E}, \\
10^{11} \mathrm{~Pa}\end{array}$ \\
\hline $\mathrm{x}=0.1$ & 64.382 & & 1.5 & \\
$\mathrm{x}=0.3$ & 64.475 & 5.590 & 6.3 & 1.230 \\
$\mathrm{x}=0.5$ & 64.383 & 5.581 & 4.1 & 1.216 \\
$\mathrm{x}=1.0$ & 64.234 & 5.510 & 2.5 & 1.009 \\
$\mathrm{x}=2.0$ & 64.168 & 5.680 & 2.0 & 1.380 \\
\hline
\end{tabular}

the region of the $\mathrm{FE}$ phase transition of $0.95 \mathrm{BaTiO}_{3}-0.05 \mathrm{PbTiO}_{3}$ ceramics doped with cobalt up to 2 wt.\%.

\section{Samples and measurement method}

The studied samples of ceramic solid solution $\mathrm{Ba}_{0.95} \mathrm{~Pb}_{0.05} \mathrm{TiO}_{3}+\mathrm{x}$ wt.\% $\mathrm{Co}_{2} \mathrm{O}_{3}$ $(\mathrm{BPTC}(\mathrm{x}))(x=0.3,0.5,1.0,2.0 \mathrm{wt} . \%)$ were obtained from high-purity grade oxides by conventional solid phase 2 -stage synthesis. The mixture was mixed with ethanol, ground in ball mill during $24 \mathrm{~h}$, dried, and calcinated for $2 \mathrm{~h}$ at $1300^{\circ} \mathrm{C}$. The obtained BPTC(x) samples were ground and homogenised in ball mill, after which the ceramics were produced by consecutive sintering under atmospheric conditions for $2 \pm 1 \mathrm{~h}$ at $1400 \pm 50{ }^{\circ} \mathrm{C}$. The completeness of synthesis and crystallographic structure of sintered samples phase constitution were examined by X-ray diffraction using a PANalytical X'Pert PRO diffractometer. The density of samples was determined by hydrostatic weigh method. For dielectric measurements the parallel surfaces of specimens were furnished with silver paste electrodes at $500{ }^{\circ} \mathrm{C}$ for 15 minutes.

The obtained ceramic samples have perovskite structure (up to 98\%); X-ray diffraction patterns show the tetragonal cell; some samples with $\mathrm{x} \geq 1.0 \mathrm{wt} . \% \mathrm{Co}_{2} \mathrm{O}_{3}$ have a weakly expressed rhombic distortion.

The unit cell of the BPTC has a tendency to decrease with an increase of Co content in the solid solution (see Table 1). The analysis of the ion radii and the evaluation of the $\mathrm{Co}$ ions take place in $\mathrm{ABO}_{3}$ unit cell may provide clarification. If Co ions are situated in $\mathrm{A}$ sublattice with coordination number $12, \mathrm{Ba}$ ion radius is $\mathrm{R}_{\mathrm{Ba}}=1.61$; lead ion radius is $\mathrm{R}_{\mathrm{Pb}}=1.49$; average for $\mathrm{Ba}_{0.95} \mathrm{~Pb}_{0.05} \mathrm{TiO}_{3}$ solid solution is $\mathrm{R}_{\mathrm{BaPb}}=1.604$, and $\mathrm{R}_{\mathrm{Co}}=0.80$ [10]. If Co ions are situated in $\mathrm{B}$ sublattice with coordination number 6 , then $\mathrm{R}_{\mathrm{Ti}}=0.60$ and $\mathrm{R}_{\mathrm{Co}}=0.53$. Hence, the volume of the unit cell decreases if Co is situated either in A or B sublattice. Taking into account the sufficient difference in the ion radii of $\mathrm{Ba}$ and $\mathrm{Pb}$ ions, on one hand, and $\mathrm{Co}$ ions, on the other hand, the replacement of A-ions with Co seems unlikely.

With an increase of Co content above $1 \%$, the decrease of the volume of the unit cell becomes slower, which points at the saturation of the amount of the embedded Co (see Table 1).

The microstructure of different compositions was studied by scanning electron microscope (SEM) using a Phenom Pro model. The typical microstructure of the BPTC(x) ceramics is shown in Figure 1. The microstructure of $\operatorname{BPTC}(x)$ ceramics has a variable morphology. 
(a)

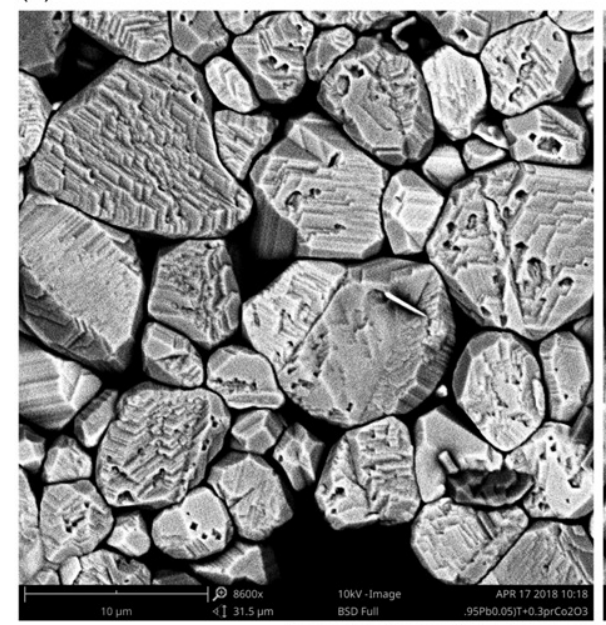

(b)

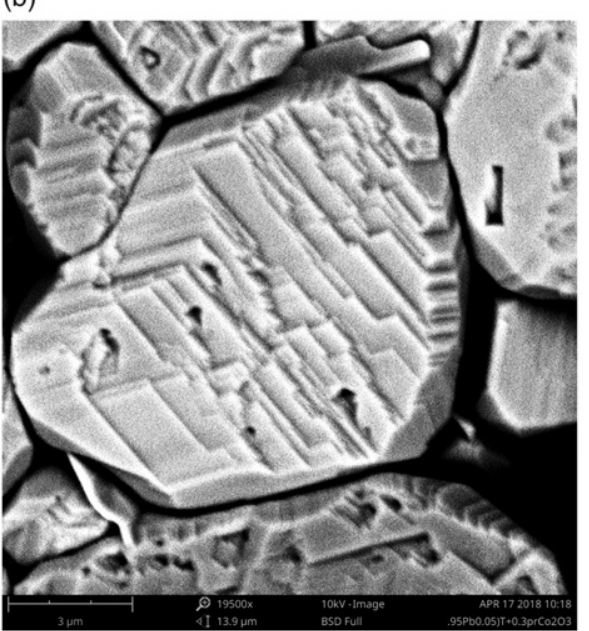

(c)

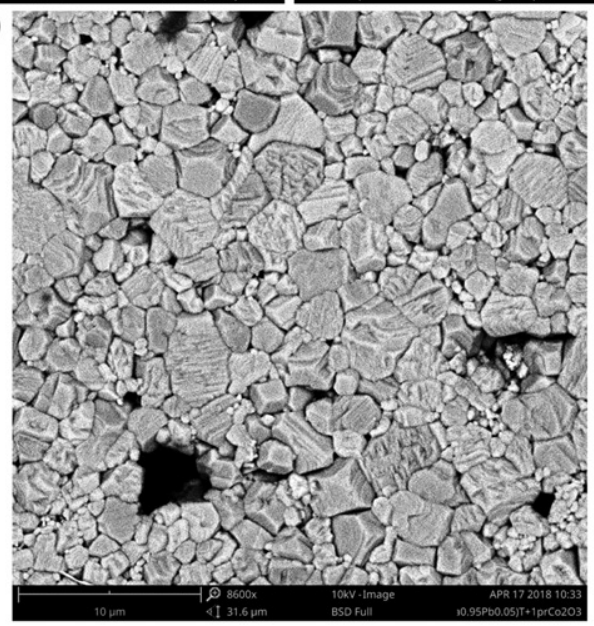

Figure 1. Microstructure of samples $\mathrm{Ba}_{0.95} \mathrm{~Pb}_{0.05} \mathrm{TiO}_{3}+\mathrm{x}$ wt.\% $\mathrm{CO}_{2} \mathrm{O}_{3}: \mathrm{a}-\mathrm{x}=0.3$, magnification $8600 \times ; b-x=0.3$, magnification 19500 $x ; c-x=1.0$, magnification $8600 \times$.

In composition with $\mathrm{x}=0.3$ the mean size of grains increases to $6.3 \mu \mathrm{m}$. In the etched samples, layers of the grain growth are clearly visible (Figure 1(b)). In the samples with $\mathrm{x} \geq 1.0$, the grains are smaller and the distribution of grain size is not as broad as in low Co content ceramics.

For dielectric measurements in weak fields (RLC metre E7-15), samples with silver electrodes in diameter of $\varnothing 15 \mathrm{~mm}$ and a thickness of $0.5 \mathrm{~mm}$ were used. Temperature dependences of the real part $\varepsilon^{\prime}(\mathrm{T})$ and the imaginary part $\varepsilon^{\prime \prime}(\mathrm{T})$ of dielectric permittivity in a weak measuring field were carried out at the frequencies of 100 and $1000 \mathrm{~Hz}$ in a heating regime with a heating rate of $0.5 \mathrm{deg} / \mathrm{min}$.

The velocity of longitudinal sound waves was measured using a resonance method on the samples prepared in the form of $15 \mathrm{~mm}$ long and $1.5 \times 1.5 \mathrm{~mm}^{2}$ thick bars. The electrodes were applied to the longest edges of the bars. The samples were poled in a constant electric field $\mathrm{E}=10 \mathrm{kV} / \mathrm{cm}$ at $\mathrm{T}>100^{\circ} \mathrm{C}$, followed by cooling in the field to room temperature $\left(\mathrm{T}_{\text {room }}\right)$. 

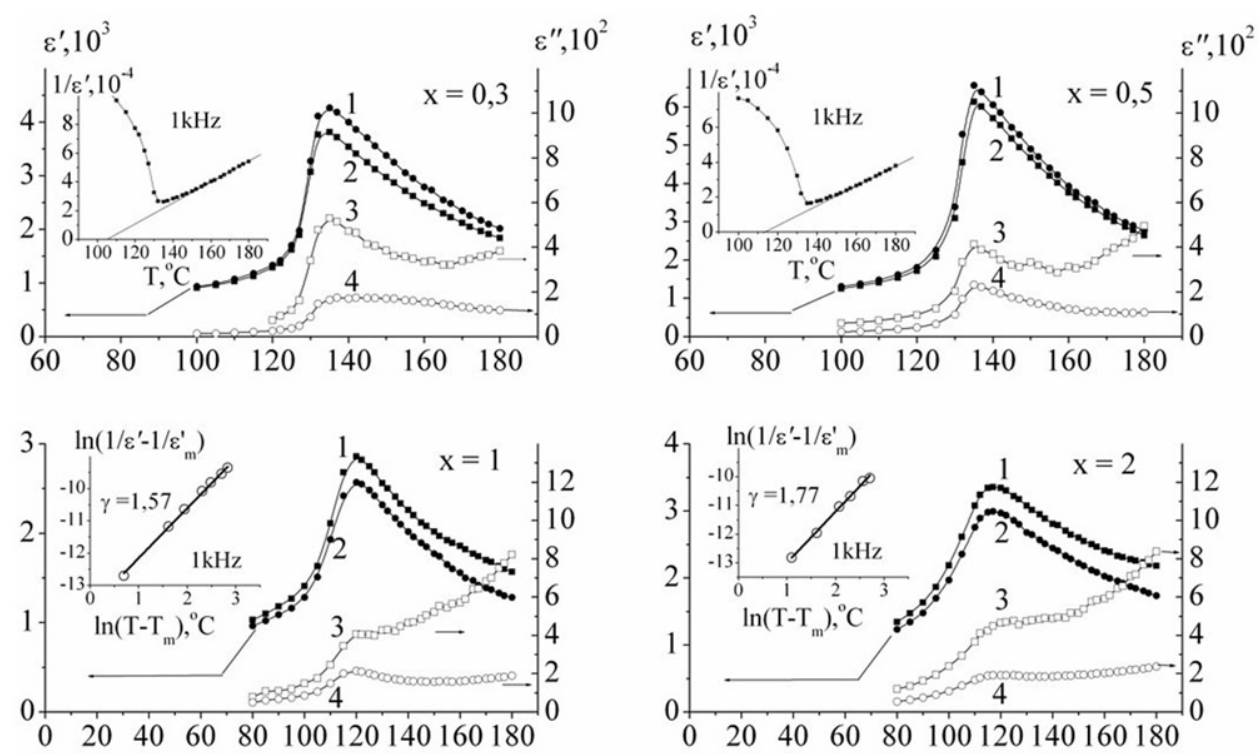

$\mathrm{T},{ }^{\circ} \mathrm{C}$

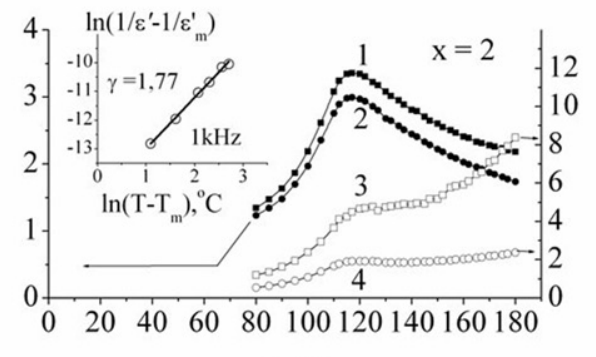

$\mathrm{T},{ }^{\circ} \mathrm{C}$

Figure 2. Temperature dependences of $\varepsilon^{\prime}(\mathrm{T})$ (curves 1, 2) and $\varepsilon^{\prime \prime}(\mathrm{T})$ (curves 3, 4) in $\mathrm{Ba}_{0.95} \mathrm{~Pb}_{0.05} \mathrm{TiO}_{3}+x \mathrm{Co}_{2} \mathrm{O}_{3}$ ceramics with different cobalt content $\mathrm{x}$ at frequencies $100 \mathrm{~Hz}$ (curves 1,3 ) and $1000 \mathrm{~Hz}$ (curves 2, 4).

\section{Experimental results and discussion}

Temperature dependences of the real $\left(\varepsilon^{\prime}\right)$ and imaginary part $\left(\varepsilon^{\prime \prime}\right)$ of the dielectric constant in $\mathrm{Ba}_{0.95} \mathrm{~Pb}_{0.05} \mathrm{TiO}_{3}+x \mathrm{Co}_{2} \mathrm{O}_{3}$ (BPTC(x)) ceramics with different values of cobalt content: $x=0.3,0.5,1.0,2.0 \mathrm{wt} . \%$ (Figure 2) show that the temperature of the maximum $\mathrm{T}_{\mathrm{m}}$ at 100 and $1000 \mathrm{~Hz}$ practically does not shift with frequency inherent to relaxor ferroelectrics and thus, the temperature $T_{m}$ should be considered as the mean temperature of the PT from the ferroelectric phase to the paraelectric phase. The anomalies in the region of the FE phase transition with increasing of cobalt content are broadening, and the temperature $T_{m}$ itself decreases. The broadening of PT is especially noticeable at concentrations $\mathrm{x}=1$ and $\mathrm{x}=2$. In the inset of Figure 2 for compositions with $\mathrm{x}=0.3$ and $\mathrm{x}=0.5$, the dependence of the inverse dielectric permittivity on the temperature $1 / \varepsilon^{\prime}(\mathrm{T})$ in $\mathrm{T}_{\mathrm{m}}$ region show that the Curie-Weiss law is satisfied in a definite region starting with $\mathrm{T}>\mathrm{T}_{\mathrm{m}}$. For compositions with $\mathrm{x}=1$ and $\mathrm{x}=2$ for which the maximum of $\varepsilon^{\prime}(\mathrm{T})$ broadens, the inset shows the dependences of the difference of the reciprocal permittivities $\left(1 / \varepsilon^{\prime}-1 / \varepsilon_{\mathrm{m}}^{\prime}\right)$ on the temperature difference $\left(\mathrm{T}-\mathrm{T}_{\mathrm{m}}\right)$ in logarithmic scale in the temperature range $\mathrm{T}>\mathrm{T}_{\mathrm{m}}$. This representation of the behaviour of the dielectric response is quite often used to estimate the degree of broadening of the PT in ferroelectric relaxors, for example, in the doped $\mathrm{Pb}\left(\mathrm{Mg}_{1 / 3} \mathrm{Nb}_{2 / 3}\right) \mathrm{O}_{3}-\mathrm{Pb}\left(\mathrm{Zr}_{0.49} \mathrm{Ti}_{0.51}\right) \mathrm{O}_{3}$ ceramics [11], when the degree of broadening of the PT is characterised by the parameter $\gamma$ in the expression $1 / \varepsilon^{\prime}-1 / \varepsilon_{\mathrm{m}}^{\prime}=\mathrm{a}\left(\mathrm{T}-\mathrm{T}_{\mathrm{m}}\right)^{\gamma} \cdot 1 / \varepsilon^{\prime}(\mathrm{T})$ curves at $\mathrm{x}=0.3$ and $\mathrm{x}=0.5$ show that in the composition with $\mathrm{x}=0.3$ the deviation from the Curie-Weiss law occurs over a wider temperature interval $\left(\mathrm{T}-\mathrm{T}_{\mathrm{m}}\right)$ than for the composition with $\mathrm{x}=0.5 . \varepsilon(\mathrm{T})$ 
(a)

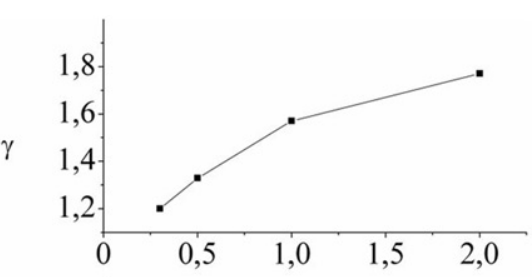

(b)
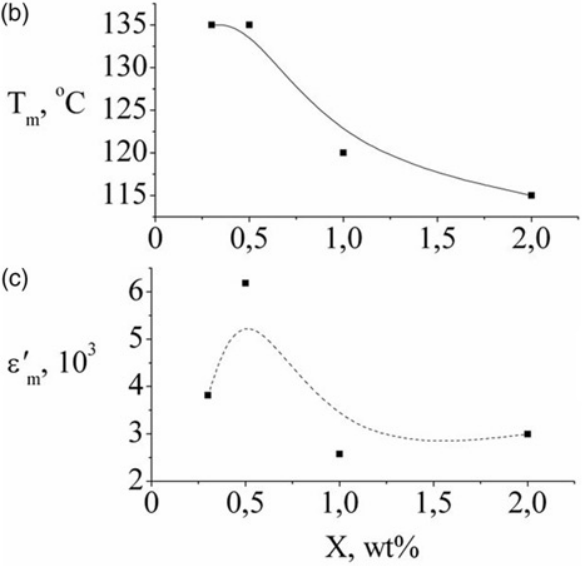

Figure 3. Concentration dependences of $\gamma(x), T_{m}(x)$ и $\varepsilon_{m}^{\prime}(x)$ in BPTC $(x)$ ceramics.

dependence in the temperature range $\mathrm{T}>\mathrm{T}_{\mathrm{m}}$ in all samples were evaluated for the degree of broadening of the PT, with respect to the parameter $\gamma$ (Figure 3(a)).

Figure 3(a) illustrates the concentration dependence $\gamma(\mathrm{x})$ for BPTC ceramics. It is evident that for $\mathrm{x}=0.3$ and $\mathrm{x}=0.5$, the value of $\gamma$ differs slightly from 1 . This difference becomes significant when $\mathrm{x} \geq 1$. Thus, with an increase in cobalt concentration to $\mathrm{x}=2$, the parameter $\gamma \approx 1.8$, indicating that the dependence approaches a quadratic one, as in model ferroelectrics with diffuse PT [12]. At $\mathrm{x}<1$, there is no noticeable effect of Co concentration on $\mathrm{T}_{\mathrm{m}}$ as follows from Figure 3(b). Figure 3(c) shows the behaviour of the concentration dependences of the maxima of dielectric permittivity $\varepsilon_{\mathrm{m}}(\mathrm{x})$ at $\mathrm{T}_{\mathrm{m}}$; a significant difference occurs for concentration $\mathrm{x}=0.5$, where $\varepsilon_{\mathrm{m}}^{\prime}$ values are much higher than for other cobalt concentrations, which may occur due to the large grains (Table 1; Figure 1).

At a frequency of $100 \mathrm{~Hz}$, the maxima of $\varepsilon^{\prime \prime}(\mathrm{T})$ curves for $\mathrm{x} \geq 1$ are substantially smoothed, only a break in the curve in the PT region is observed, after which a noticeable increase in the dielectric losses occurs. This growth is associated with a significant contribution of conductivity in the compositions with an increased cobalt concentration [13].

Figure $4(\mathrm{a}, \mathrm{b})$ illustrate the behaviour of the longitudinal sound velocity $\mathrm{v}(\mathrm{T})$ in the temperature region both below $\mathrm{T}_{\mathrm{m}}$ (composition with $\mathrm{x}=0.5$ ) and in the region $\mathrm{T}>\mathrm{T}_{\mathrm{m}}$ for the composition with $\mathrm{x}=2$. The points on the graphs indicate the experimentally obtained velocities for a given material, and the dashed lines are the approximations in the form of $\mathrm{v}=\mathrm{A}+\mathrm{B} \times\left(\mathrm{T}-\mathrm{T}_{\mathrm{c}}\right)^{\mathrm{p}}$, where $\mathrm{A}$ and $\mathrm{B}$ are the experiment constants, $\mathrm{T}_{\mathrm{c}}$ is the adjustable Curie temperature, which practically coincides with the values of $T_{m}$, and the parameter $\mathrm{p}$ describes the decrease rate of sound velocity in the region of PT. The 

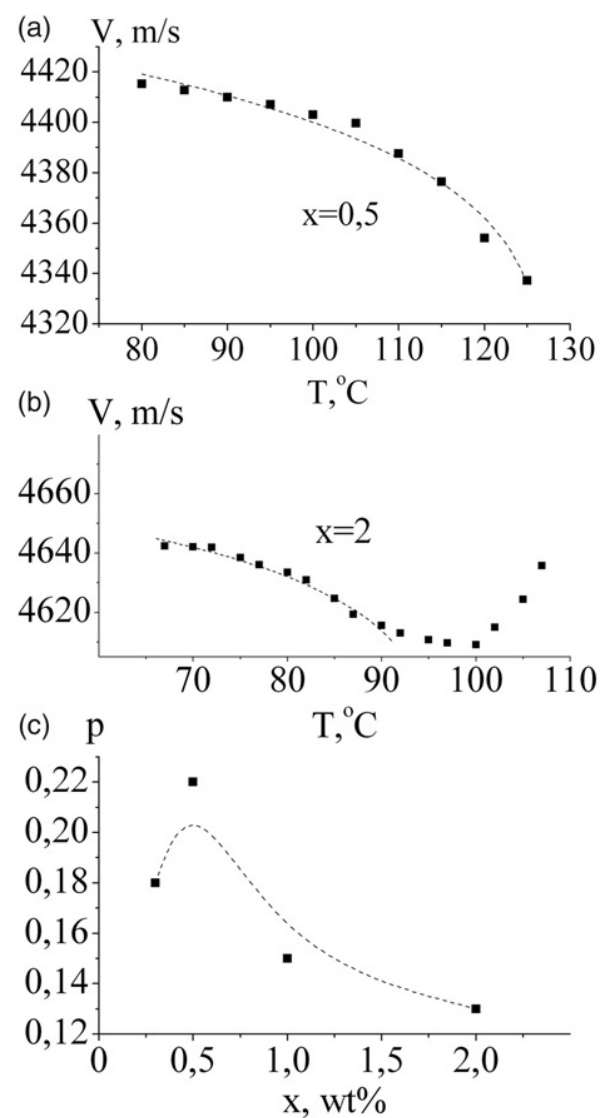

Figure 4. Temperature dependences of the longitudinal velocity of sound and their approximation by the power-law dependence in the PT region for the compositions BPTC $(x)$, where $x=0.5(a), x=2$ (b), and concentration dependences of the exponent $\mathrm{p}(\mathrm{x})$ (c) in the $\mathrm{Ba}_{0.95} \mathrm{~Pb}_{0.05} \mathrm{TiO}_{3}+\mathrm{xCO}_{2} \mathrm{O}_{3}$.

dependencies of such a type describe the behaviour of the sound velocity in ferroelectrics with diffuse PT $[14,15]$.

Figure 4(c) represents the concentration dependence of the parameter $\mathrm{p}$ in the BPTC ceramics. Sample with $\mathrm{x}=0.5$ demonstrates the highest values of $\mathrm{p}$ and the highest values of $\varepsilon_{\mathrm{m}}^{\prime}$ (Figure $3(\mathrm{c})$ ), which describes this composition as the one with the least diffused PT. The lowest values of the ultrasound velocity are observed for $x=1$. This result relies on the low density of ceramics of a given composition, which is manifested in the concentration dependences of the density $\rho(\mathrm{x})$ (Table 1) and calculated Young's modulus $E_{Y}=4 \rho l^{2} f_{r}^{2}$, where 1 - length of the sample, $f_{r}$ - resonance frequency.

\section{Conclusions}

Studying the effect of $\mathrm{Co}$ on the dielectric and elastic properties of the $(1-x) \mathrm{Ba}_{0.95} \mathrm{~Pb}_{0.05} \mathrm{TiO}_{3}+x \mathrm{Co}_{2} \mathrm{O}_{3}(x=0.3,0.5,1.0,2.0 \mathrm{wt} . \%)$, revealed that

1. Phase transition is shifted in the direction of low temperatures upon increasing of Co concentration; 
2. The nature of the dielectric response and the behaviour of the ultrasonic velocity in BPTC compositions have shown that the phase transition at $\mathrm{x}>1 \%$ becomes substantially diffused, and can be described in the framework of existing approaches in ferroelectrics with diffuse PT.

\section{Disclosure statement}

No potential conflict of interest was reported by the authors.

\section{Funding}

This work was supported in part by the Ministry of Education and Science of the Russian Federation.

\section{References}

[1] B. L. Cheng et al., Mechanical loss and Young's modulus associated with phase transitions in barium titanate based ceramics, J. Mater. Sci. 31(18), 4951 (1996).

[2] J. Brančin, and L. Medveck, Influence of mechanical activation of precursors on the structure and properties of donor doped $\mathrm{Ba}_{0.95} \mathrm{~Pb}_{0.05} \mathrm{TiO}_{3}$ ceramics, J. Mater. Sci. Lett. 21, 55 (2002).

[3] J. F. Meng et al., Study of visible emission and phase transition in nanocrystalline $\mathrm{A}_{(1-}$ ${ }_{\text {x) }} \mathrm{A}^{\prime}{ }_{\mathrm{x}} \mathrm{TiO}_{3}$ systems, Phys. Lett. A 229, 254 (1997). DOI: 10.1016/S0375-9601(97)00152-7.

[4] A. V. Myasoedov, and S. R. Syrtsov, Positive temperature coefficient of resistance in the lead-containing ceramic barium titanate, Tech. Phys. 42(9), 1097 (1997). DOI: 10.1134/ 1.1258783 .

[5] A. I. Lebedev et al., XAFS studies of the local environment of $\mathrm{Pb}$ impurity atoms in barium, strontium, and calcium titanates, Phys. Solid State 51(5), 991 (2009). DOI: 10.1134/ S1063783409050175.

[6] H. J. Hagemann, and H. Ihring, Valence change and phase stability of $3 \mathrm{~d}$ doped $\mathrm{BaTiO}_{3}$ annealed in oxygen and hydrogen, Phys. Rev. B 20, 3871 (1979). DOI: 10.1103/ PhysRevB.20.3871.

[7] E. Markiewicz et al., Effect of cobalt doping on the dielectric response of $\mathrm{Ba}_{0.95} \mathrm{~Pb}_{0.05} \mathrm{TiO}_{3}$ ceramics, J. Electroceram. 32(1), 92 (2014). : DOI: 10.1007/s10832-013-9865-1.

[8] W. Li et al., Doping behaviors of $\mathrm{Nb}_{2} \mathrm{O}_{5}$ and $\mathrm{Co}_{2} \mathrm{O}_{3}$ in temperature stable $\mathrm{BaTiO}_{3}$-based ceramics, Mat. Lett. 57(1), 1 (2002). DOI: 10.1016/S0167-577X(02)00687-0.

[9] Q. Li et al., Improvement of temperature stable $\mathrm{BaTiO}_{3}$-based dielectrics by addition of $\mathrm{Li}_{2} \mathrm{CO}_{3}$ and $\mathrm{Co}_{2} \mathrm{O}_{3}$, J. Eur. Ceram. Soc. 21(12), 2217 (2001). DOI: 10.1016/S09552219(01)00194-7.

[10] R. D. Shannon, Revised effective ionic radii and systematic studies of interatomic distances in halides and chalcogenides, Acta Cryst. A 32, 751 (1976). DOI: 10.1107/ S0567739476001551.

[11] X. Zhang et al., Effect of $\mathrm{Cr}_{2} \mathrm{O}_{3}$ modification on dielectric, ferroelectric and fieldinduced strain properties of $0.18 \mathrm{~Pb}\left(\mathrm{Mg}_{1 / 3} \mathrm{Nb}_{2 / 3}\right) \mathrm{O}_{3}-0.82 \mathrm{~Pb}\left(\mathrm{Zr}_{0.49} \mathrm{Ti}_{0.51}\right) \mathrm{O}_{3}$ ceramics, J. Mater. Sci: Mater. Electron. 29, 3602 (2018). DOI: 10.1007/s10854-017-8290-7.

[12] G. A. Smolensky et al., Physics of ferroelectric phenomena, Science, Leningrad. 396 (1985). (in Russian).

[13] R. Bujakiewicz-Koronska et al., Physical properties of $(1-x) \mathrm{Ba}_{0.95} \mathrm{~Pb}_{0.05} \mathrm{TiO}_{3}+x \mathrm{Co}_{2} \mathrm{O}_{3}$ $(x=0,0.1,0.3,0.5,1.0,2.0 \mathrm{wt} \%)$ ceramics, Ceram. Int. 41(3), 3983 (2015). DOI: 10.1016/ j.ceramint.2014.11.083. 
[14] A. S. Pilipenko, A. I. Burkhanov, and L. I. Ivleva, Evolution of the dielectric and acoustic parameters of chromium-doped SBN single crystals with variations in temperature, Phys. Solid State. 51(3), 577 (2009). DOI: 10.1134/S1063783409030238.

[15] E. Smirnova et al., Acoustic properties of multiferroic $\mathrm{PbFe}_{1} /{ }_{2} \mathrm{Ta}_{1} /{ }_{2} \mathrm{O}_{3}$, Phys. Lett. A 374, 4256 (2010). DOI: 10.1016/j.physleta.2010.08.039.

Institute of Solid State Physics, University of Latvia as the Center of Excellence has received funding from the European Union's Horizon 2020 Framework Programme H2020-WIDESPREAD-01-2016-2017- 